\title{
Dosimetric response of fabricated Ge-doped optical fibres in computed tomography RQT beam quality x-ray beams
}

\begin{abstract}
Novel germanium (Ge)-doped silica glass fibres tailor-made in Malaysia are fast gaining recognition as potential media for thermoluminescence (TL) dosimetry, with active research ongoing into exploitation of their various beneficial characteristics. Investigation is made herein of the capability of these media for use in diagnostic imaging dosimetry, specifically at the radiation dose levels typically obtained in conduct of Computed Tomography (CT). As a first step within such efforts, there is need to investigate the performance of the fibres using tightly defined spectra, use being made of a Philips constant potential industrial x-ray facility, Model MG165, located at the Malaysian Nuclear Agency Secondary Standards Dosimetry Lab (SSDL). Standard radiation beam qualities (termed RQT) have been established for CT, in accord with IEC 61267: 2003 and IAEA Technical Reports Series No. 457: 2007. A calibrated ionisation chamber has also been utilised, forming a component part of the SSDL equipment. The fabricated fibres used in this study are $2.3 \mathrm{~mol} \%$ flat fibre (FF) of dimensions $643 \times 356 \mu \mathrm{m} 2$ and $2.3 \mathrm{~mol} \%$ cylindrical fibre (CF) of $481 \mu \mathrm{m}$ diameter, while the commercial fibre used is $4 \mathrm{~mol} \%$ with core diameter of $50 \mu \mathrm{m}$. The dopant concentrations are nominal preform values. The fibres have been irradiated to doses of 20, 30 and 40 milligray (mGy) for each of the beam qualities RQT 8, RQT 9 and RQT 10. For $\mathrm{X}$-rays generated at constant potential values from 100 to $150 \mathrm{kV}$, a discernible energy-dependent response is seen, comparisons being made with that of lithium fluoride ( $\mathrm{LiF}$ ) thermoluminescence dosimeters (TLD-100). TL yield versus dose has also been investigated for x-ray doses from 2 to $40 \mathrm{mGy}$, all exhibiting linearity. Compared to TLD-100, greater sensitivity is observed for the fibres.
\end{abstract}

Keyword: Ge-doped; Computed tomography; RQT; Beam quality; X-ray beams 
